\title{
A helium-based model for the effects of radiation damage annealing on helium diffusion kinetics in apatite
}

\author{
Chelsea D. Willett ${ }^{\mathrm{a}, \mathrm{b},{ }^{*},}$, Matthew Fox ${ }^{\mathrm{a}, \mathrm{b}, \mathrm{c}}$, David L. Shuster ${ }^{\mathrm{a}, \mathrm{b}}$ \\ ${ }^{\text {a }}$ Department of Earth and Planetary Science, 307 McCone Hall, University of California, Berkeley, CA 94720, USA \\ ${ }^{\mathrm{b}}$ Berkeley Geochronology Center, 2455 Ridge Road, Berkeley, CA 94709, USA \\ ${ }^{\mathrm{c}}$ current address: Department of Earth Sciences, University College London, Gower Street, London WC1E 6BT, UK \\ ${ }^{*}$ Corresponding author. \\ Email address: chelsea.d.willett@gmail.com (C.D. Willett)
}

\begin{abstract}
Widely used to study surface processes and the development of topography through geologic time, $(\mathrm{U}-\mathrm{Th}) / \mathrm{He}$ thermochronometry in apatite depends on a quantitative description of the kinetics of ${ }^{4} \mathrm{He}$ diffusion across a range of temperatures, timescales, and geologic scenarios. Empirical observations demonstrate that He diffusivity in apatite is not solely a function of temperature, but also depends on damage to the crystal structure from radioactive decay processes. Commonly-used models accounting for the influence of thermal annealing of radiation damage on He diffusivity assume the net effects evolve in proportion to the rate of fission track annealing, although the majority of radiation damage results from $\boldsymbol{\alpha}$-recoil. While existing models adequately quantify the net effects of damage annealing in many geologic scenarios, experimental work suggests different annealing rates for the two damage types. Here, we introduce an alpha-damage annealing model (ADAM) that is independent of fission track annealing kinetics, and directly quantifies the influence of thermal annealing on $\mathrm{He}$ diffusivity in apatite. We present an empirical fit to diffusion kinetics data and incorporate this fit into a model that tracks the competing effects of radiation damage accumulation and annealing on He diffusivity in apatite through geologic time. Using time-temperature paths to illustrate differences between models, we highlight the influence of damage annealing on data interpretation. In certain, but not all, geologic scenarios, the interpretation of low-temperature thermochronometric data can be strongly influenced by which model of radiation damage annealing is assumed. In particular, geologic scenarios involving 1-2 km of sedimentary burial are especially sensitive to the assumed rate of annealing and its influence on He diffusivity. In cases such as basement rocks in Grand Canyon and the Canadian Shield, (U-Th)/He ages predicted from the ADAM can differ by hundreds of Ma from those predicted by other models for a given thermal path involving extended residence between $\sim 40-80^{\circ} \mathrm{C}$.
\end{abstract}




\section{INTRODUCTION}

Over the past two decades, $(\mathrm{U}-\mathrm{Th}) / \mathrm{He}$ thermochronometry in apatite has been widely used to study surface processes and topography development through geologic time (e.g., Reiners and Brandon 2006). Because the diffusion of $\mathrm{He}$ in apatite is sensitive to temperatures found in the uppermost few kilometers of Earth's crust, the production and diffusion of radiogenic ${ }^{4} \mathrm{He}$ via $\boldsymbol{\alpha}$-decay of radioactive nuclides (i.e. along the $\mathrm{U}$ - and Th-series decay chains) can be used to quantify the timing, rates, and spatial patterns of exhumation over typically $>0.1$ million year (Ma) timescales (e.g., Farley 2002). A quantitative description of the diffusion kinetics of ${ }^{4} \mathrm{He}$ in apatite is required for accurate interpretation of $(\mathrm{U}-\mathrm{Th}) / \mathrm{He}$ data. Complexity in the kinetic function has been revealed by empirical observations that He diffusivity in apatite is not solely a function of temperature, but may also evolve as a function of damage to the apatite crystal structure resulting from $\boldsymbol{\alpha}$-recoil and fission events (Shuster et al. 2006; Flowers et al. 2009; Shuster and Farley 2009; Gautheron et al. 2009). Damage from $\boldsymbol{\alpha}$-recoil has recently been mapped in zircon (Valley et al. 2014), revealing small pockets of damage capable of trapping He (Shuster et al. 2006; Flowers et al. 2009; Shuster and Farley 2009; Gautheron et al. 2009) and other elements. The radiation damage content in a crystal will increase as a function of time, at a rate proportional to parent nuclide concentration, but will also decrease in response to thermal heating (Shuster and Farley 2009). The effects of thermal annealing of radiation damage and its influence on He diffusivity complicates the problem of quantifying ${ }^{4} \mathrm{He}$ diffusivity through time, as the diffusivity at any point in time will be influenced by the sample's prior thermal path. A quantitative understanding of the competing effects of radiation damage accumulation and annealing is necessary to accurately model and interpret the results of all (U-Th)/He thermochronometric data, but especially in scenarios involving reheating over geologic time (e.g., due to sedimentary burial). 
Previous treatments of the accumulation and annealing of radiation damage in apatite have recently been challenged by observations in certain geologic scenarios, demonstrating the important influence of the assumed rate of annealing on (U-Th)/He data interpretation (e.g., Fox and Shuster 2014). Existing models, now commonly used to interpret (U-Th)/He data, make the fundamental assumption that the net effects of radiation damage in apatite, which primarily result from $\boldsymbol{\alpha}$-recoil damage, can be quantified using empirical models of apatite fission track (AFT) annealing (Flowers et al. 2009; Gautheron et al. 2009). This assumption - that fission tracks and $\boldsymbol{\alpha}$-recoil damage anneal, and in response control He diffusivity, at the same rate adequately describes the effects of annealing in many geologic scenarios. However, measurements of optical properties suggest that annealing rates of damage resulting from $\boldsymbol{\alpha}$-recoil and fission events in apatite likely differ (Ritter and Märk 1986). Should the annealing of fission tracks be less resistant to annealing, perhaps as a function of damage geometry and size, the previous diffusion models would overpredict the rate of damage annealing and underpredict the $(\mathrm{U}-\mathrm{Th}) / \mathrm{He}$ age.

Here, we present a new alpha-damage annealing model (ADAM) that quantifies the influence of thermal annealing on He diffusivity without relying on the assumption that $\boldsymbol{\alpha}$-recoil damage anneals at a rate that is ultimately tied to the annealing of fission tracks. The ADAM instead quantifies the effects of annealing with empirical relationships calibrated by experimentally-controlled damage annealing and He diffusion kinetics data, thus providing an internally consistent and more direct relationship between $\boldsymbol{\alpha}$-recoil damage annealing and $\mathrm{He}$ diffusivity. We present an empirical fit to data of Shuster and Farley 2009, which quantify the resulting effects of annealing temperature and duration on He diffusivity. By assuming these 
experimental results are extrapolatable to longer times and lower temperatures, we incorporate the calibrated functions into a numerical model that tracks the competing effects of radiation damage accumulation and annealing on He diffusivity in apatite; we show evolutions of radiation damage, diffusion kinetics, and the (U-Th)/He age through geologic time. We compare the results of this new model framework with existing models (Farley 2000; Flowers et al. 2009) and demonstrate that in certain, but not all, geologic scenarios, the interpretation of low-temperature thermochronometric data can be strongly influenced by the assumed model of radiation damage annealing.

\section{A NEW FRAMEWORK FOR QUANTIFYING THE EFFECTS OF ANNEALING}

Predicting (U-Th)/He ages for a given apatite sample requires specifying the diffusivity of $\mathrm{He}$ as it evolves through geologic time and temperature (Farley 2002; Shuster et al. 2006; Shuster and Farley 2009; Flowers et al. 2009; Gautheron et al. 2009). As in previous treatments of this problem, the ADAM calculates the production and diffusion of ${ }^{4} \mathrm{He}$ in a finite crystal domain based on the grain size, $U$ and Th concentrations, temperature, and the damage concentration in the crystal. The ADAM assumes the accumulation of radiation damage causes He diffusivity to decrease, following empirical relationships calibrated in (Shuster and Farley 2009; Flowers et al. 2009). However, unlike other models, the ADAM assumes that the annealing of damage from spontaneous fission events and damage from $\boldsymbol{\alpha}$-recoil do not necessarily occur at the same rate, or even a scaleable rate. Experimental work measuring the effects of thermal annealing conditions in apatite found large differences based on the type of radiation damage (i.e. fission track versus $\boldsymbol{\alpha}$-recoil), quantified by optical properties (Ritter and Märk 1986). We calibrate the annealing portion of the ADAM using experimentally-determined diffusion kinetics data (Shuster and Farley 2009). Employing an empirical fit to diffusion data produces a simpler, more direct 
relationship between damage concentration and He diffusion, and — importantly — restores independence between models, and thus interpretations, of (U-Th)/He and fission track systems in apatite.

The experiments of Shuster and Farley 2009 systematically measure changes in He diffusivity by varying the annealing temperature and duration in Durango apatite; these data provide the basis for our empirical fits integrated into the ADAM. Shuster and Farley 2009 present diffusivity or closure temperature (Dodson 1973), both derivative quantities of activation energy $\left(E_{a}\right)$ and the pre-exponential term $\left(D_{0} / a^{2}\right)$ in the Arrhenius relation for diffusivity. Here, we use the reported values of $E_{a}$ and $\ln \left(D_{0} / a^{2}\right)$ in Table 2 of that work. Because we are interested in how diffusion kinetics parameters change in response to annealing conditions, the results are expressed as differences between the measured $E_{a}$ and $\ln \left(D_{0} / a^{2}\right)$ values in the suite of annealed samples and the sample with no preheating. Figure 1 shows the (Shuster and Farley 2009) results in this form, plotting the systematic changes in $\mathrm{E}_{\mathrm{a}}\left(\Delta \mathrm{E}_{\mathrm{a}}\right)$ in Figure $1 \mathrm{~A}$ and the changes in $\ln \left(\mathrm{D}_{0} / \mathrm{a}^{2}\right)\left(\Delta \ln \left(\mathrm{D}_{0} / \mathrm{a}^{2}\right)\right)$ in Figure 1B.

Based on previously published results (Shuster et al. 2006; Shuster and Farley 2009; Flowers et al. 2009), we sought a mathematical expression to relate temperature, heating duration, and diffusion kinetics with two goals. First, the expression needed to reach maximum and minimum values at low and high temperatures, respectively. That is, no change to diffusion kinetics occurs at very low temperatures, and above some combination of duration and sufficiently high temperature, the parameters reach values characteristic of a fully annealed (or damage-free) crystal: $122.3 \mathrm{~kJ} / \mathrm{mol}$ for $E_{a}$ and $9.733 \ln \left(\mathrm{s}^{-1}\right)$ for $\ln \left(D_{0} / a^{2}\right)$ (Flowers et al. 2009). Second, we required the $\Delta \mathrm{E}_{\mathrm{a}}$ and $\Delta \ln \left(\mathrm{D}_{0} / \mathrm{a}^{2}\right)$ to depend on both temperature and duration. We thus chose an 
empirical relationship between annealing temperature, annealing duration, and diffusion kinetics that both adequately describes the available experimental data, and predicts the expected behavior at very low and very high temperatures. We adapted a functional form previously used to quantify similar effects in damage annealing (Laslett et al. 1987), and use two expressions that describe resulting changes in He diffusion kinetics directly: one for $\Delta \mathrm{E}_{\mathrm{a}}$ and one for $\Delta \ln \left(D_{0} / a^{2}\right):$

\section{Equation 1:}

$$
\ln \left[-\ln \left(\frac{\Delta E_{a}}{c_{3-} E_{a}}-1\right)\right]=c_{1-} E_{a}+\ln (t)+c_{2-} E_{a} * T^{-1}
$$

Equation 2:

$$
\ln \left[-\ln \left(\frac{\Delta \ln D_{0} / a^{2}}{c_{3-} D_{0}}-1\right)\right]=c_{1-} D_{0}+\ln (t)+c_{2-} D_{0} * T^{-1}
$$

where $t$ is duration of thermal annealing at temperature $T, \mathrm{c}_{1}$ and $\mathrm{c}_{2}$ (for $\mathrm{E}_{\mathrm{a}}$ and $\mathrm{D}_{0}$ ) are empirically fit parameters, and $c_{3-} E_{a}$ and $c_{3} D_{0}$ are calculated values, described below.

To quantify the best-fitting set of parameters for Equations 1 and 2, we conducted a systematic search of parameter combinations. The tested values for $c_{1-} E_{a}$ and $c_{1-} D_{0}$ range from 55 to 65 and the values for $C_{2} E_{a}$ and $c_{2} D_{0}$ range from -25000 to -19000 , with both ranges divided into 101 linearly-spaced values. These ranges were selected to encompass combinations of fits that plot near the data and complete the search at an informative resolution. The quantities $c_{3} E_{a}$ and $c_{3} D_{0}$ are differences between the observed values of $E_{a}$ and $\ln \left(D_{0} / a^{2}\right)$ for natural (i.e., non-annealed) Durango apatite (Figure 1) and the assumed values of $E_{a}$ and $\ln \left(D_{0} / a^{2}\right)$ for fully annealed apatite, as defined above. These $c_{3}$ values, effectively vertical scaling coefficients, exert a primary control on the amount of (and maximum possible) change in diffusivity that occurs in response to annealing during each time step. For the empirical fits, we also required all values to be above the minimum values for fully annealed apatite (Flowers et al. 2009), and thus exclude nine experimental results with lower values. To calibrate our function, we use data 
of 14 annealing and diffusion experiments conducted between 17 and $365^{\circ} \mathrm{C}$ for between 1 to 350 hours.

For each combination of the four parameters, we calculate a chi-squared misfit value between the observed values (i.e., of either $\Delta \mathrm{E}_{\mathrm{a}}$ or $\left.\Delta \ln \left(\mathrm{D}_{0} / \mathrm{a}^{2}\right)\right)$ and their respective model prediction for a given annealing condition. To be consistent with experimental results (Shuster et al. 2006; Shuster and Farley 2009), after modifying $E_{a}$ and $\ln \left(D_{0} / a^{2}\right)$ by annealing (i.e., for a given set of parameter values) we also require diffusivity to be the same or higher over modeled temperatures of 0 to $600^{\circ} \mathrm{C}$ and up to 10-Ma steps. Each set of four parameters is tested together and must result in increasing (or unchanging) diffusivity; the $\Delta \mathrm{E}_{\mathrm{a}}$ or $\Delta \ln \left(\mathrm{D}_{0} / \mathrm{a}^{2}\right)$ pairs can not be considered independently.

As in Flowers et al. 2009, we use a proxy to track total radiation damage and its annealing. The "effective damage density" (EDD) evolves through model time and provides an empirical relationship between an abundance of radiation damage and the diffusion kinetics of a given sample. At the start of each time step, the ADAM calculates the number of decays from $U$ and Th concentrations and converts those decays into an effective damage value using the damage addition relationship from Flowers et al. 2009 (Section 4). This multiplies the number of decays by the ratio of the fission and $\boldsymbol{\alpha}$-decay constants and the net length of fission fragments from decay of ${ }^{238} \mathrm{U}$. This is added to the previous EDD and then used to determine the $E_{a}$ and $\ln \left(\mathrm{D}_{0} / \mathrm{a}^{2}\right)$ of the sample using the relationships between $\mathrm{E}_{\mathrm{a}}$ and ETD ("effective track density") and $\ln \left(\mathrm{D}_{0} / \mathrm{a}^{2}\right)$ and ETD (Flowers et al. 2009). Note ETD and EDD are comparable, but given different names to emphasize that damage in the ADAM is not tied to the AFT system. For a temperature and duration, $\mathrm{E}_{\mathrm{a}}$ and $\ln \left(\mathrm{D}_{0} / \mathrm{a}^{2}\right)$ are then modified according to Equations 1 and 2 , 
respectively, using the $E_{a}$ and $\ln \left(D_{0} / a^{2}\right)$ at that step to calculate the $c_{3}$ values used. The new $E_{a}$ and $\ln \left(D_{0} / a^{2}\right)$ values are used to calculate He diffusivity and, in combination with the modeled ${ }^{4} \mathrm{He}$ concentration in the crystal, the model $(\mathrm{U}-\mathrm{Th}) / \mathrm{He}$ age at that time step. The resultant $\mathrm{E}_{\mathrm{a}}$ value is then used to determine the EDD after annealing has taken place, per the relationship described above. The EDD and apparent age at the end of the time step are calculated and stored, and the model moves to the next time interval.

By using Equations 1 and 2 and calculating $c_{3}$ values at each time step as the difference between the EDD-determined kinetics parameter and the corresponding minimum value, we assume that the net change in diffusion parameters at each time step will be greater when the amount of damage present in the crystal is higher. We also assume that these experimentally-calibrated expressions can be extrapolated over geologic timescales. We discuss each assumption and its implications in Section 4.

\section{RESULTS}

\subsection{Best-fit model parameters}

Figure 1 shows the best-fit result for the functions for both $\Delta E_{a}$ and $\Delta \ln \left(D_{0} / a^{2}\right)$ and the data used for calibration. The best-fit values for the four parameters are: $c_{1} E_{a}=58.6, c_{2-} E_{a}=-21280$, $c_{2} D_{0}=58.4$, and $c_{2} D_{0}=-21700$. The constraint on the tested parameter sets is shown in Figure 2 as a "heat map" of parameter pairs colored by their chi-square misfit. The parameter pairs for $\Delta \mathrm{E}_{\mathrm{a}}$ and for $\Delta \ln \left(\mathrm{D}_{0} / \mathrm{a}^{2}\right)$ cannot be chosen independently based on misfit values in panel A and panel B; doing so would circumvent the described diffusivity test. Model sensitivity and parameter covariance are discussed in Section 4. 


\subsection{Model comparisons and implications}

We compare the ADAM with the Radiation Damage Accumulation and Annealing Model (RDAAM; Flowers et al. 2009) to illustrate cases where different treatments of radiation damage annealing influence the modeling and interpretation of data. Using five reference time-temperature (t-T) scenarios (Wolf et al. 1998), Figure 3 compares model apatite (U-Th)/He ages through time for both the ADAM and RDAAM using an effective uranium concentration value (eU, computed as $[\mathrm{U}]+0.235^{\star}[\mathrm{Th}]$; Gastil et al. 1967) of 28 parts per million (ppm), 'typical' of apatite samples used in low-temperature thermochronology studies (Flowers et al. 2009). Unless otherwise specified, the model crystal is unzoned and the grain size is 70 microns for both models throughout this publication.

The He Partial Retention Zone (HePRZ) is the range of temperatures over which the modeled He age changes rapidly in a particular phase: low temperatures cause near-quantitative $\mathrm{He}$ retention whereas high temperatures cause higher rates of diffusive loss of $\mathrm{He}$ (Wolf et al. 1998). At $>80^{\circ} \mathrm{C}$ or $<40^{\circ} \mathrm{C}$ for the majority of the model run (i.e., outside the HePRZ), the ADAM and RDAAM predict indistinguishable ages (Figure 3A, 3B). For these cases of rapid exhumation or simple cooling, this means that the two models will produce essentially identical results, supporting the conclusions of many published low-temperature thermochronology studies. Scenarios that result in significantly different model ages (Figure 3C - 3E) are t-T paths that include substantial durations in HePRZ temperatures of $40-80^{\circ} \mathrm{C}$, where the influence of damage annealing is significantly different between the models. In Figure 3E, a slow heating followed by relatively rapid cooling, the ADAM predicts an age 30 percent older than the age calculated by the RDAAM for the same model inputs. These results demonstrate that the choice of annealing model can greatly influence data interpretation in cases where the temperature of a 
given sample is thought to increase and then decrease with time, as in cases of deep reburial during sedimentation.

The model results from Figure 3 are shown as a ratio through time in Figure 4, with the ADAM ages normalized to ages calculated by other models. Figure 4A compares the ADAM to model ages calculated assuming the diffusion kinetics of Durango apatite (Farley 2000), and shows that only the path that begins at surface temperatures followed by reheating predicts an age for the ADAM that is older than that for Durango kinetics. In the other four cases, the ages calculated assuming Durango kinetics are equal to or older than the ages from the ADAM. Figure 4B normalizes the ADAM ages to the RDAAM and demonstrates that the RDAAM predicts a higher rate of increase in diffusivity due to damage annealing (i.e. resulting in younger ages) than does the ADAM for the entirety of these specific t-T scenarios and when eU is 28 ppm. The eU ultimately controls which model will predict an older or younger age for a given t-T scenario, and is explored in the following two sections.

\subsubsection{The HePRZ and the influence of eU}

To illustrate the behavior of the HePRZ using the ADAM, we calculate (U-Th)/He ages for samples held for 75 million years at constant temperatures ranging from 0 to $120^{\circ} \mathrm{C}$ and $\mathrm{eU}$ values from 4 to $150 \mathrm{ppm}$ (Figure $5 \mathrm{~A}$ ). The curves calculated using Durango diffusion kinetics (Farley 2000) and AFT thermochronometry (Ketcham et al. 2007) are included for comparison. The HePRZ for the ADAM shows a similar sigmoidal shape; however, as is the case of the RDAAM, the temperature range of the ADAM HePRZ changes based on the eU in the grain. Samples of low concentration (eU of $4 \mathrm{ppm}$ ) will demonstrate this behavior over a temperature range of approximately 30 to $50^{\circ} \mathrm{C}$, while samples whose eU is $150 \mathrm{ppm}$ show a HePRZ 
between about 70 and $90^{\circ} \mathrm{C}$. Higher parent concentrations lead to more crystal damage, hence greater He retentivity and an older apparent age at a given isothermal holding temperature. The effect of grain size on the calculated HePRZ is secondary to the eU control, as is the case with the RDAAM (Flowers et al. 2009). A comparison between the ADAM and RDAAM for these isothermal conditions is shown in Figure 5B. For both models, there is a positive, nonlinear correlation between (U-Th)/He age and eU. This dependence on eU is most strongly pronounced in both models at the middle of the HePRZ temperature range, at $60^{\circ} \mathrm{C}$, where the model age is as low as $\sim 3 \mathrm{Ma}$ and as high as $\sim 65 \mathrm{Ma}$. Under these conditions we also find the largest differences in predicted ages between the two models, by as much as 65 percent. Simulated ages from the two models are models' ages; however, this difference in modeled age is less pronounced in cases of very low and very high eU values (see Figure S1). 


\subsubsection{Continuous thermal path examples}

The influence of radiation damage annealing on the apatite (U-Th)/He system will be most pronounced in scenarios that involve gradual reheating through geologic time (Figure 3). Thus, any inaccuracy in, and differences between, kinetics models are most likely revealed in samples that experienced such conditions. As an example to illustrate the sensitivity of both models to reheating, we consider data collected from basement rocks from the bottom of Grand Canyon (Flowers et al. 2008; Flowers and Farley 2012; Winn et al. 2017'; Fox et al. 2017'). The t-T path shown in Figure $6 \mathrm{~A}$ is at Earth surface temperatures for 172 million years, then increases to 80 ${ }^{\circ} \mathrm{C}$ over roughly 210 million years, simulating slow reheating via deep sedimentary burial. After residing at $80^{\circ} \mathrm{C}$ for 30 million years, temperature slowly decreases to $60^{\circ} \mathrm{C}$ over a 90-million-year period, where it remains until rapidly decreasing from $60^{\circ} \mathrm{C}$ to $0{ }^{\circ} \mathrm{C}$ in the final 6 million years of simulated time. This individual path, consistent with a "young canyon" model (Karlstrom et al. 2008; Flowers and Farley 2012; Karlstrom et al. 2014), obeys the constraints used to search potential western Grand Canyon t-T paths in Fox and Shuster 2014. The predicted apatite $(\mathrm{U}-\mathrm{Th}) / \mathrm{He}$ ages as they evolve through time are shown in the bottom panel of Figure $6 \mathrm{~A}$ for both models and two eU values. As with Figure 3 and Figure $\mathrm{S} 1$, the eU will influence which model predicts an older age for a given path. At the end of the thermal path, the ADAM predicts an older age than the RDAAM for low eU (10 ppm), while the opposite is true when eU is $40 \mathrm{ppm}$. This dependence on eU value is explored further below and in Figure 7.

Figure 6B shows a histogram of observed apatite (U-Th)/He ages from western Grand Canyon (Flowers et al. 2008; Flowers and Farley 2012; Winn et al. 2017') and histograms of predicted ages for the RDAAM and ADAM for the thermal path shown in Figure 6A. The models each use

\footnotetext{
${ }^{1}$ Revised manuscript for moderate revision in review with EPSL
} 
the observed $U$ and Th concentrations of the apatites shown in the data panel. For this thermal path, the model ages predicted by the ADAM are in better agreement with the measured ages and have a narrower distribution than the wide range of ages predicted by the RDAAM. In the ADAM treatment of annealing, where the net change in diffusion kinetics for a given temperature and duration increases with greater amounts of damage present, grains with high eU are predicted to be old assuming the RDAAM kinetics, but significantly younger assuming the ADAM. At low eU, and therefore lower EDD values through all time, the changes in diffusion kinetics due to annealing predicted by the ADAM are smaller than for the RDAAM, thus resulting in slightly higher He retentivity and older ages. The net effect, shown in the lower two panels of Figure $6 \mathrm{~B}$, is that for the assumed thermal path, the RDAAM predicts a larger spread in apatite $(\mathrm{U}-\mathrm{Th}) / \mathrm{He}$ ages, whereas the ADAM predicts a narrower distribution of ages. That is, the young ages predicted by the RDAAM are shifted to older ages, and very old are shifted to much younger ages by the ADAM treatment of damage annealing.

The relationships between eU and both observed and predicted apatite (U-Th)/He ages from Figure 6 are shown in Figure 7. The ADAM and RDAAM both have distinct age-eU correlation, but this dependence is less dramatic with the ADAM. Both models fail to predict the $50-100 \mathrm{Ma}$ ages for grains with low eU (i.e., $<15 \mathrm{ppm}$ ). As with the $80^{\circ} \mathrm{C}$ isothermal case in Figure 5B, for any given thermal path, there is an eU value that serves as a "crossover point": below a certain value ( 18 ppm in Figure 7 and $\sim 100$ ppm in Figure 5B) the ADAM predicts an older age, whereas the opposite is true above that value.

Previous work in western Grand Canyon calls on the complete resetting of the AFT system to constrain temperature conditions of $110-120^{\circ} \mathrm{C}$ between $\sim 100$ and $80 \mathrm{Ma}$ (Dumitru et al. 1994). 
299 When used to constrain the thermal history along with (U-Th)/He ages, these conditions 300 ultimately require an old canyon solution (i.e., reaching near-modern topography by $\sim 70 \mathrm{Ma}$ 301 (Flowers and Farley 2012)) since they predict complete resetting of apatite to maximum He diffusivity. The example young canyon path whose ADAM ages agree with measured (U-Th)/He ages, the t-T path shown in Fig. 6, does not meet those AFT resetting temperature criteria; however, the model is entirely He-based and internally consistent, in contrast to what is shown using the RDAAM in Fox and Shuster 2014. Furthermore, recent work (Winn et al. 2017') constrains t-T paths whose maximum temperatures are well below the AFT-dictated $120^{\circ} \mathrm{C}$ and demonstrates ongoing uncertainty surrounding maximum burial conditions and the timing of western Grand Canyon incision.

\section{DISCUSSION} As with other treatments of He diffusivity in apatite, applications of the ADAM require important assumptions. Here, we discuss model extrapolations from the experimental time and temperature conditions shown in Figure 1, and to different apatite characteristics. We then discuss issues specific to the ADAM and limitations of the model. Finally, we suggest a number of geologic tests that could ultimately help improve our understanding of controls on $\mathrm{He}$ diffusivity in apatite, and quantify a model framework that most accurately predicts relatively

316 low-temperature processes near Earth's surface.

\subsection{Model extrapolations}

4.1.1. Extrapolating from laboratory conditions to geologic timescales

A somewhat unique challenge in Earth and planetary science is the need to use experimental observations made on laboratory timescales to study processes and phenomena that are active 
over geologic timescales. While both models discussed in this paper are justified by laboratory data (e.g., Shuster et al. 2006; Shuster and Farley 2009), implementing either model, or other models for the (U-Th)/He system in apatite (e.g., Gautheron et al. 2009), requires the assumption that what has been determined in the lab can be accurately extrapolated to geologic timescales and temperatures. Because laboratory experiments are limited to durations orders of magnitude shorter than geologic timescales, we commonly increase experimental temperatures to achieve a similar net effect. Therefore, implementing the model necessitates extrapolation in both time and temperature, which may lead to inaccuracy as the fit proposed in this paper is not based in a physical model, but rather is based on a mathematical function chosen to fit the published data.

Because Equations 1 and 2 each contain two natural logarithms, the influence of $c_{1}$ and $c_{2}$ on the shape of the model curves is similar. Decreasing either value results in increased spacing between the duration curves and causes the rollover portion of the curves to be less steep and to begin at higher temperature (Figure S2). The $\mathrm{c}_{2}$ values have an increased temperature sensitivity due to the multiplication with inverse temperature. The trade off between $c_{1}$ and $c_{2}$ is shown by the oblong ellipses in Figure 2, a clear indication that the parameters covary.

Experiments with longer annealing times (i.e. months to years, as opposed to hours) at lower temperatures would offer a modest amount of information about model accuracy and $\mathrm{c}_{1}$ and $\mathrm{c}_{2}$ values and potentially inform the use of Equations 1 and 2 in the ADAM. Such longer experiments could serve to validate the quantitative relationship more than provide insight into geological processes and timescales, whereas certain geologic tests, discussed in Section 4.3, may offer deeper insight into extrapolation accuracy. 


\subsubsection{Influence of apatite chemistry}

The fit shown in Figure 1 was optimized using the only available experimental data on the effects of annealing of Durango apatite, which is a fluorapatite with atypically high Th concentration and a measured (U-Th)/He age of $31.02 \pm 1.01 \mathrm{Ma}$ (McDowell et al. 2005). Apatite, $\left(\mathrm{Ca}_{5}\left(\mathrm{PO}_{4}\right)_{3}(\mathrm{OH}, \mathrm{Cl}, \mathrm{F})\right)$, spans a range of anion chemical compositions, which may influence the rates of both accumulation and annealing of damage in a given apatite (Gautheron et al. 2013; Ketcham et al 1999). If so, such chemical variability could influence (U-Th)/He ages in certain thermal histories, and may therefore influence geologic interpretations if such chemical control on annealing is not properly understood. Our framework for fitting an annealing function to directly calibrate the effects of radiation damage on He diffusivity may require further refinement when additional experimental results on other apatites are collected.

\subsection{Model limitations}

\subsubsection{Model sensitivity}

The set of four parameters used in Equations 1 and 2 were selected by identifying the lowest total misfit between the calculated model curves and the published diffusion kinetics data. Although Figure 2 shows the parameter pairs and their misfit, it offers little intuition as to how sensitive our "best fit" model is. Figure S2 shows examples of model misfits colored blue and yellow in Figure 2 and confirms that the selected best-fit model appears to better visually match the data. Also note that we are limited to 14 data points in this fit; more data would allow for a better constrained fit. 


\subsection{2. $E_{a}-E D D$ limitations}

The chosen relationship between EDD and diffusion kinetics, particularly when determining the EDD after annealing at a given model time step, requires using either the $E_{a}-E D D$ or the $\ln \left(D_{0} / a^{2}\right)$-EDD relationship (Flowers et al. 2009). The determined EDD may be slightly different $(<1 \%)$ between the two. Here, we use the $E_{a}-E D D$ relationship because of the unique relationship between the variables, whereas the $\ln \left(\mathrm{D}_{0} / \mathrm{a}^{2}\right)$-EDD curve rolls over, with pairs of EDD values corresponding to a single $\ln \left(\mathrm{D}_{0} / \mathrm{a}^{2}\right)$ value. Our use of the published $\mathrm{E}_{\mathrm{a}}-\mathrm{EDD}$ relationship leads to another limitation in the ADAM, since the empirical data of Shuster et al. 2006 and relationships in Flowers et al. 2009 only span $E_{a}$ values from $122.3-156.3 \mathrm{~kJ} / \mathrm{mol}$ and EDD values between $1 \times 10^{4}$ and $1 \times 10^{7}$ tracks $/ \mathrm{cm}^{2}$. If a crystal contains much lower or higher damage concentrations, one must extrapolate beyond the available data. If any measured apatite $E_{a}$ exceeds $156.3 \mathrm{~kJ} / \mathrm{mol}$, or if an apatite is believed to be fully annealed and has an $E_{a}$ lower than $122.3 \mathrm{~kJ} / \mathrm{mol}$, a different relationship would be needed to relate these values to the corresponding EDD. Additionally, these relationships carry their own error (Flowers et al. 2009); further experimental work will improve and constrain these relationships, or something similar, and can then be incorporated into this proposed model framework.

\subsubsection{EDD-dependent annealing}

By employing Equations 1 and 2, the ADAM assumes that the absolute change to the diffusion kinetics parameters $\left(\Delta \mathrm{E}_{\mathrm{a}}\right.$ and $\left.\Delta \ln \left(\mathrm{D}_{0} / \mathrm{a}^{2}\right)\right)$ is proportional to the amount of damage present at the beginning of that time step. The RDAAM, however, calculates the damage added to the crystal structure and the quantity annealed given a t-T path based on the temperature-dependent length reduction of fission tracks in the AFT system, which is unrelated to the total amount of damage present within the crystal. Other studies have determined that in certain geologic 
conditions, the RDAAM overestimates the rate of change in diffusion kinetics resulting from fission track annealing (Gautheron et al. 2013; Fox and Shuster 2014; Ault et al. 2015). Although damage annealing rates are critical to understanding both the AFT and (U-Th)/He systems, quantifying the rates and understanding their mechanisms in both apatite and zircon is ongoing work. The rate of damage annealing has been suggested to vary with damage concentration in zircon and to occur by multiple mechanisms (Ewing et al. 2003), supporting this EDD-dependent annealing assumption made in the ADAM. Furthermore, others have used empirical data for fitting exercises similar to the one presented in this publication: Tagami et al. 1990 employ a linear relationship between track shortening and track density while Yamada et al. 2007 fit both hybrid linear and parallel-curvilinear fits for AFT in zircon, demonstrating the diversity in functional form used to quantify radiation damage annealing.

The amount of pre-existing damage in an apatite may influence the relationship between the rate of annealing and He diffusivity. For example, the mechanism of damage annealing may differ in the condition of very little damage or in the condition of approaching a percolation point, where the effective He diffusivity is expected to increase substantially due to intersecting zones of damage (Shuster et al. 2006; Trachenko et al. 2002; Ewing et al. 2003; Trachenko 2004; Ketcham et al. 2013; Guenthner et al. 2013). Future experiments on the effects of reheating temperature and duration on He diffusion kinetics in a range of apatite samples would test these outlined assumptions, particularly the scaling of the functions via the evolving $c_{3} E_{a}$ and $c_{3} D_{0}$ parameters. For example, experiments could be conducted on very young and very old apatite samples or apatites with synthetically-generated radiation damage (Shuster et al. 2006). Such experiments would help evaluate whether the effects of thermal annealing on He diffusion kinetics depend on the amount of pre-existing damage. 
Recent work in atom-probe tomography suggests that direct visualization of $\boldsymbol{\alpha}$-recoil damage is possible in apatite. The technique has been used in zircon (Valley et al. 2014) and offers the potential to both visualize and quantify damage content. Conducting these analyses on apatites at different stages of thermal annealing could provide a direct means of quantifying the rates of damage addition and thermal annealing, perhaps in tandem with indirect observations of spatial variations in damage obtained through step degassing and spatial mapping of parent nuclides in apatite grains (Fox et al. 2014).

\subsection{Model validations}

The largest source of uncertainty in the ADAM framework is the extrapolation of kinetic relationships through geologic time. In principle, geologic scenarios with independent knowledge of a reheating and cooling path could provide validation for laboratory-based empirical relationships. However, such scenarios often do not provide sufficient geologic precision for a definitive test. In Figure 6, we use the example of a hypothetical western Grand Canyon thermal path to illustrate differences between the ADAM and RDAAM. Although Grand Canyon provides a valuable, illustrative case, it does not provide an unambiguous test of thermochronometric model accuracy due to geologic uncertainty in the $\mathrm{t}-\mathrm{T}$ path of each sample before, during, and after sedimentary burial. Here, we consider the merits of published tests and propose possible tests to validate the ADAM and other models.

\subsubsection{What tests have been considered in the past?}

Flowers et al. 2009 use a number of example datasets as plausibility tests of the RDAAM. They use data from eight basement samples collected from the Upper Granite Gorge (UGG) in 
eastern Grand Canyon to test the hypothesis that the RDAAM should predict correlation between apatite (U-Th)/He age and eU. While a specified thermal path with the RDAAM successfully predicts the observed data, this test does not necessarily prove that the kinetic model is accurate; another model may also be consistent with the same data and a different, yet geologically permissible, thermal path. In such geologic tests, we commonly lack adequate precision, accuracy, and independent knowledge of a thermal path to confirm model accuracy.

However, the UGG test clearly demonstrates that the RDAAM predicts the data better than the Durango model (Farley 2000), and also provides a valuable test for the ADAM. Interestingly, using the RDAAM-determined thermal path, the ADAM predicts the measured ages slightly better (Figure S3). Although both models can successfully predict the observations, this scenario does not provide a particularly sensitive test for distinguishing between the two damage models due to the geologic setting, which involves cooling from $120^{\circ} \mathrm{C}$ at $80 \mathrm{Ma}$ to $5^{\circ} \mathrm{C}$ today. The simple cooling path resembles the test shown in Figure 3B, wherein the two models calculate nearly indistinguishable results. Geologic scenarios that mimic the tests shown in Figure 3E (reheating) or Figure 5B (constant temperature) would provide a better means to test radiation damage models and are described in Section 4.3.2.

Flowers et al. 2009 also consider seven samples from the Canadian Shield. For this example, the RDAAM predicts an age-eU relationship that matches the data better than the ADAM (Figure S4). However, lowering the temperature of the RDAAM-determined path between 1200 and $720 \mathrm{Ma}$ by $<12{ }^{\circ} \mathrm{C}$ brings the ADAM into better agreement with measured data, and causes the RDAAM to systematically overpredict age. While these natural tests can reveal subtleties of the models, the lack of sufficient precision and independent knowledge of past $\mathrm{t}-\mathrm{T}$ conditions 
renders these scenarios unable to test which model more accurately quantifies effects of $\boldsymbol{\alpha}$-recoil damage annealing.

\subsubsection{Proposed additional geologic tests}

A natural experiment to test the accuracy of these models over long timescales would be highly informative. However, identifying sites with sufficient and independent knowledge of low-temperature thermal conditions is challenging. One potential test of the ADAM and other models is to use borehole samples, where the relationships between (U-Th)/He thermochronometric ages, absolute depth, and distances between samples is known and temperatures can be assumed to have been relatively constant for extended durations. For example, apatites collected from the KTB borehole in Germany (e.g. Warnock et al. 1997; Guralnik et al. 2015) are assumed to have been at nearly constant temperatures for $\sim 25 \mathrm{Ma}$ (Guralnik et al. 2015). Figure 5B indicates that analyses of individual crystals spanning a range of eU should provide a sensitive test of the model accuracy. In particular, substantial differences between the ADAM and RDAAM should be resolvable in samples at $\sim 60^{\circ} \mathrm{C}$. However, existing apatite (U-Th)/He data from KTB samples were measured on multiple crystals simultaneously (Warnock et al. 1997; Guralnik et al. 2015). From single crystal observations of borehole — or otherwise isothermal — samples, and correlation between $\mathrm{eU}$ and He ages, one can test whether the ADAM, RDAAM, or some other model is most successful in a plot such as Figure 5B. Such data would not only provide a test of a given model framework, but could also help develop or refine existing model parameters.

Other geologic scenarios can also be used to verify models on timescales that are short by geologic standards but far exceed the constraints laboratory timeframes. Little Devil's Postpile, 
474 California, is an $~ 8 \mathrm{Ma}$ basalt intrusion into apatite-bearing Sierran granite. Its emplacement caused a thermal perturbation of granite that previously resided at low temperatures for tens of $\mathrm{Ma}$, and can be considered a natural, long-term reheating experiment. The basalt intrusion created a thermal gradient that extended up to 16 meters from the contact (Calk and Naeser 1973; Shuster et al. 2012). Measured and modeled (U-Th)/He ages in conjunction with diffusion experiments and thermal modeling of the intrusion offers another natural test of the ADAM and other kinetic models of annealing and diffusivity.

\section{CONCLUSIONS}

We present a new quantitative treatment of the annealing of radiation damage and its control on He diffusivity in apatite, and illustrate its influence on the modeling and interpretation of low temperature $\mathrm{U}-\mathrm{Th} / \mathrm{He}$ thermochronology data. Instead of assuming that thermal annealing of $\boldsymbol{\alpha}$-recoil damage must be tied to the annealing of fission tracks in apatite, we fit an empirical set of expressions to published He diffusivity data to more directly, and independently, quantify the effects of thermal annealing on He diffusivity in Durango apatite. The resulting ADAM calculates similar ages to other models in many simple geologic cases but yields different results during extended residence in the HePRZ or when held at low temperatures and subsequently reheated to $\sim 40-80^{\circ} \mathrm{C}$. The ADAM predicts age-eU correlation, though it is less strong than predicted by the RDAAM in the cases we explore. We use a hypothetical example of burial reheating followed by exhumation that obeys the constraints used in studies of western Grand Canyon (Fox and Shuster 2014). This demonstrates that the new treatment of radiation damage annealing permits at least one young canyon scenario to be constrained by observed apatite $(\mathrm{U}-\mathrm{Th}) / \mathrm{He}$ ages. We propose additional experimental work on apatite of differing chemistry, age, and damage content to help confirm or re-evaluate the necessary assumptions made in the 
497 construction of this model, and ultimately improve our quantitative understanding of the $498(\mathrm{U}-\mathrm{Th}) / \mathrm{He}$ system in apatite. 


\section{Acknowledgments}

This work was supported by an NSF Graduate Research Fellowship (to C.D.W.), the University of California, Berkeley Larsen Fund (to D.L.S.) and the NSF Tectonics Program (EAR-1347990 to D.L.S.). We acknowledge support of the Ann and Gordon Getty Foundation.

\section{Supplementary Materials}

4 figures with captions.

\section{Figure Captions}

Figure 1. Model fits to experimental data for annealed Durango apatite. (A) Measured $E_{a}$ from Shuster and Farley 2009 (data points), along with the best-fit curves identified by the misfit minimization of Equation 1 (lines). (B) Data and best-fit result for $\ln \left(D_{0} / a^{2}\right)$ and Equation 2. In both panels, the left $y$-axis is a change in each diffusion parameter relative to unannealed Durango apatite (yellow circle), while the right $y$-axis is the absolute value of the parameter. The $\mathrm{C}_{3}$ value shown in each panel is specific to the kinetics of Durango apatite.

Figure 2. Model parameter misfit and optimization. (A) Pairs of $c_{1} E_{a}$ and $c_{2} E_{a}$ from Equation 1 , colored by reduced chi-square misfit calculated between the model predictions and data shown in Figure 1. (B) Pairs of $c_{1} D_{0}$ and $c_{2} D_{0}$ from Equation 2, colored by reduced chi-square value. Color bar indicates the reduced chi-square misfit where red is low and blue is high. White squares indicate the parameter pairs for the best fit. The gray contour in each panel shows the estimated $95 \%$ confidence interval. Note that the two pairs of parameters (i.e., those for $E_{a}$ and those for $\left.\ln \left(D_{0} / a^{2}\right)\right)$ cannot be selected independently, as all four parameters must be tested together.

Figure 3. Comparisons of ADAM and the RDAAM using five canonical time-temperature paths from (Wolf et al. 1998) and an eU of 28 ppm. Both models use a 100,000-year time step and predict nearly identical ages through time in cases where temperatures reside mostly outside the HePRZ (A and B). Paths with the longest residence in the HePRZ result in the largest difference between model ages (C, D and E). See Figure S1 for very low and very high eU values.

Figure 4. Comparisons of model age through time for the five t-T paths used in Figure 3. (A) $(\mathrm{U}-\mathrm{Th}) / \mathrm{He}$ ages predicted using the ADAM normalized to ages calculated using the kinetics for Durango apatite (Farley 2000). (B) ADAM ages normalized to the RDAAM through model time. For eU of $28 \mathrm{ppm}$, the ADAM consistently predicts an equal or older age than the RDAAM, suggesting that the RDAAM may be over-annealing damage for certain eU values.

Figure 5. Comparisons of model ages for isothermal conditions. (A) Calculated apatite $(\mathrm{U}-\mathrm{Th}) / \mathrm{He}$ ages for a range temperatures and eU values for $75 \mathrm{Ma}$ of isothermal holding using the ADAM. We also show ages calculated assuming Durango apatite diffusion kinetics (black 
dash-dot line; Farley 2000) and apatite fission track ages (grey dashed line; Ketcham et al. 2007) for comparison. (B) Calculated apatite (U-Th)/He ages for both models as a function of eU for $20,40,60$, and $80^{\circ} \mathrm{C}$ and a hold time of $75 \mathrm{Ma}$. For the lowest three temperatures, the ADAM predicts ages that are systematically older than those predicted by the RDAAM. In the case of the $80^{\circ} \mathrm{C}$ isothermal hold, a crossover in models occurs.

Figure 6. A comparison of the ADAM and the RDAAM, using a hypothetical t-T path corresponding to a young-canyon model of western Grand Canyon. Chosen here to illustrate differences between the two kinetic models, Panel $A$ is an example of a young canyon thermal path that is compatible with available data and shows calculated (U-Th)/He ages through time for eU values of 10 and $40 \mathrm{ppm}$. Panel B shows a histogram of the measured ages (green) and the ages predicted by the two different kinetic models (gray and black) using the observed values of eU. While both models are sensitive to $\mathrm{eU}$, this example demonstrates that for this assumed thermal path, the spread of $(\mathrm{U}-\mathrm{Th}) / \mathrm{He}$ ages calculated by the RDAAM is far broader than that predicted assuming the ADAM.

Figure 7. A comparison of measured and predicted apatite (U-Th)/He ages versus the measured eU for published data from western Grand Canyon (green circles, data from Flowers and Farley 2012; Winn et al., in revision) assuming the hypothetical t-T path shown in Figure 6A. The RDAAM results (black squares) show a stronger age dependence on eU for this t-T path than the modeled ages of this study (gray diamonds). Both models fail to predict the high ages $(50-100 \mathrm{Ma})$ at low eU (<15 ppm). 


\section{References}

Ault, A.K., P.W. Reiners, S.N. Thomson, and G. H. Miller. 2015. "Inverted apatite (U-Th)/He and fission-track dates from the Rae Craton, Baffin Island, Canada and implications for apatite radiation damage-He diffusivity models." American Geophysical Union Fall Meeting, San Francisco.

Calk, L.C., and C.W. Naeser. 1973. "The thermal effect of a basalt intrusion on fission tracks in quartz monzonite." Geology 81 (2): 189-198.

Dodson, M.H. 1973. "Closure temperature in cooling geochronological and petrological systems." Contributions to Mineralogy and Petrology 40: 259-274.

Dumitru, T.A., I.R. Duddy, and P.F. Green. 1994. "Mesozoic-Cenozoic burial, uplift, and erosion history of the west-central Colorado Plateau." Geology 22 (6): 499-502.

Ewing, R.C., A. Meldrum, L. Wang, W.J. Weber, and L.R. Corrales. 2003. "Radiation effects in zircon." Reviews in Mineralogy and Geochemistry 53 (1): 387-425.

Farley, K.A. 2000. "Helium diffusion from apatite: General behavior as illustrated by Durango fluorapatite." Journal of Geophysical Research 105: 2903-2914.

Farley, K.A. 2002. "(U-Th)/He Dating: Techniques, Calibrations, and Applications." Reviews in Mineralogy and Geochemistry 47 (1): 819-844.

Flowers, R.M., and K.A. Farley. 2012. "Apatite ${ }^{4} \mathrm{He} /{ }^{3} \mathrm{He}$ and $(\mathrm{U}-\mathrm{Th}) / \mathrm{He}$ evidence for an ancient Grand Canyon." Science 338 (6114): 1616-1619.

Flowers, R.M., R.A. Ketcham, D.L. Shuster, and K.A. Farley. 2009. "Apatite (U-Th)/He thermochronometry using a radiation damage accumulation and annealing model." Geochimica et Cosmochimica Acta 73 (8): 2347-2365.

Flowers, R.M., B.P. Wernicke, and K.A. Farley. 2008. "Unroofing, incision, and uplift history of the southwestern Colorado Plateau from apatite (U-Th)/He thermochronometry." Geological Society of America Bulletin 120 (5-6): 571-587.

Fox, M., R.E. McKeon, and D.L. Shuster. 2014. "Incorporating 3-D parent nuclide zonation for apatite ${ }^{4} \mathrm{He} /{ }^{3} \mathrm{He}$ thermochronometry: An example from the Appalachian Mountains." Geochemistry, Geophysics, Geosystems 15 (11): 4217-4229.

Fox, M., and D.L. Shuster. 2014. "The influence of burial heating on the (U-Th)/He system in apatite: Grand Canyon case study." Earth and Planetary Science Letters 397: 174-183.

Gastil, R. Gordon, M. DeLisle, and J.R. Morgan. 1967. "Some effects of progressive metamorphism on zircons." Geological Society of America Bulletin 78 (7): 879-906.

Gautheron, C., J. Barbarand, R.A. Ketcham, L. Tassan-Got, P. van der Beek, M. Pagel, R. Pinna-Jamme, F. Couffignal, and M. Fialin. 2013. "Chemical influence on a-recoil damage annealing in apatite: Implications for (U-Th)/He dating." Chemical Geology 351: 257-267.

Gautheron, C., L. Tassan-Got, J. Barbarand, and M. Pagel. 2009. "Effect of a-damage annealing 
on apatite (U-Th)/He thermochronology." Chemical Geology 266 (3-4): 157-170.

Guenthner, W.R., P.W. Reiners, R.A. Ketcham, L. Nasdala, and G. Giester. 2013. "Helium diffusion in natural zircon: Radiation damage, anisotropy, and the interpretation of zircon (U-Th)/He thermochronology." American Journal of Science 313 (3): 145-198.

Guralnik, B., M. et al. 2015. "OSL-Thermochronometry of feldspar from the KTB Borehole, Germany." Earth and Planetary Science Letters 423: 232-243.

Karlstrom, K.E., R. Crow, L.J. Crossey, D. Coblentz, and J. W. Van Wijk. 2008. "Model for tectonically driven incision of the younger than $6 \mathrm{Ma}$ Grand Canyon." Geology 36 (11): 835-838.

Karlstrom, K.E. et al. 2014. "Formation of the Grand Canyon 5 to 6 million years ago through integration of older palaeocanyons." Nature Geoscience 7 (3): 239-244.

Ketcham, R.A., A. Carter, R.A. Donelick, J. Barbarand, and A.J. Hurford. 2007. "Improved modeling of fission-track annealing in apatite." American Mineralogist 92 (5-6): 799-810.

Ketcham, R.A., R.A. Donelick, and W.D. Carlson. 1999. "Variability of apatite fission-track annealing kinetics: III. Extrapolation to geological time scales." American Mineralogist 84: $1235-1255$.

Ketcham, R.A., W.R. Guenthner, and P.W. Reiners. 2013. "Geometric analysis of radiation damage connectivity in zircon, and its implications for helium diffusion." American Mineralogist 98 (2-3): 350-360.

Laslett, G. M., P. F. Green, I. R. Duddy, and A. J. W. Gleadow. 1987. "Thermal annealing of fission tracks in apatite 2. A quantitative analysis." Chemical Geology 65: 1-13.

McDowell, F.W., W.C. McIntosh, and K.A. Farley. 2005. "A precise ${ }^{40} \mathrm{Ar}-{ }^{39} \mathrm{Ar}$ reference age for the Durango apatite (U-Th)/He and fission-track dating standard." Chemical Geology 214 (3): 249-263.

Reiners, P.W., and M.T. Brandon. 2006. "Using thermochronology to understand orogenic erosion." Annual Review of Earth and Planetary Sciences 34 (1): 419-466.

Ritter, W., and T.D. Märk. 1986. "Radiation damage and its annealing in apatite." Nuclear Instruments and Methods in Physics Research 814: 314-322.

Shuster, D.L., and K.A. Farley. 2009. "The influence of artificial radiation damage and thermal annealing on helium diffusion kinetics in apatite." Geochimica et Cosmochimica Acta 73 (1): 183-196.

Shuster, D.L., R.M. Flowers, and K.A. Farley. 2006. "The influence of natural radiation damage on helium diffusion kinetics in apatite." Earth and Planetary Science Letters 249 (3-4): $148-161$.

Shuster, D. L., P. W. Reiners, J. L. Schmidt, P. K. Zeitler, R. A. Ketcham, and L. Karlstrom. 2012. "Intercalibration of multiple thermochonometric systems at the Little Devil's Postpile contact aureole." American Geophysical Union Fall Meeting, San Francisco. 
Tagami, T., H. Ito, and S. Nishimura. 1990. "Thermal annealing characteristics of spontaneous fission tracks in zircon." Chemical Geology 80 (2): 159-169.

Trachenko, K. 2004. "Understanding resistance to amorphization by radiation damage." Journal of Physics. Condensed Matter 16 (49): 1491-1515.

Trachenko, K., M.T. Dove, and E.K.H. Salje. 2002. "Large swelling and percolation in irradiated zircon." Journal of Physics. Condensed Matter 15 (2): L1-L7.

Valley, J.W. et al. 2014. "Hadean age for a post-magma-ocean zircon confirmed by atom-probe tomography." Nature Geoscience 7 (3): 219-23.

Warnock, A. C., P. K. Zeitler, R. A. Wolf, and S. C. Bergman. 1997. "An evaluation of low-temperature apatite U-Th/He thermochronometry." Geochimica et Cosmochimica Acta 61 (24): 5371-5377.

Wolf, R. A., K. A. Farley, and D. M. Kass. 1998. "Modeling of the temperature sensitivity of the apatite (U-Th)/He thermochronometer." Chemical Geology 148: 105-114.

Yamada, R., M. Murakami, and T. Tagami. 2007. "Statistical modelling of annealing kinetics of fission tracks in zircon; Reassessment of laboratory experiments." Chemical Geology 236 (1-2): 75-91. 
Figure 1
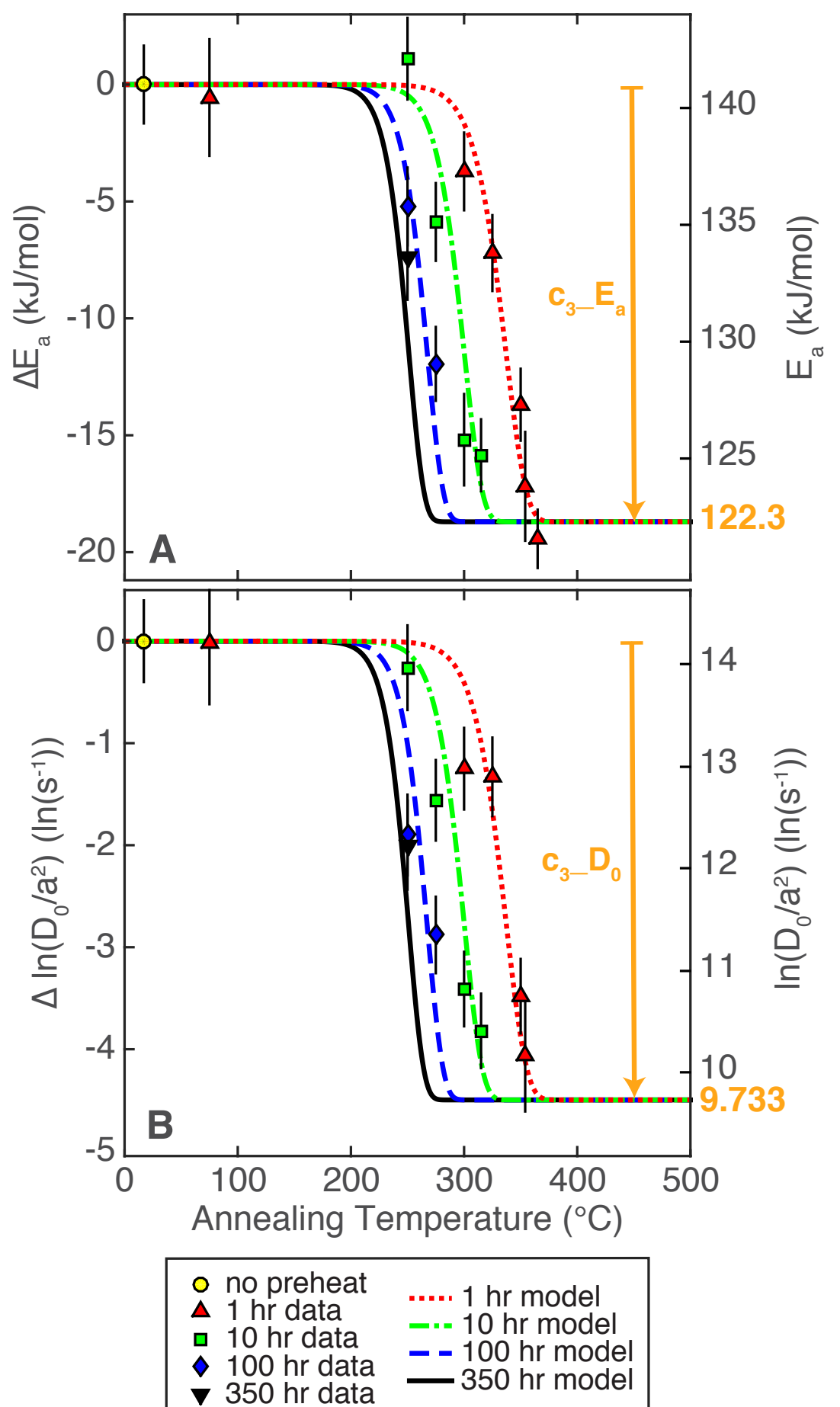
Figure 2

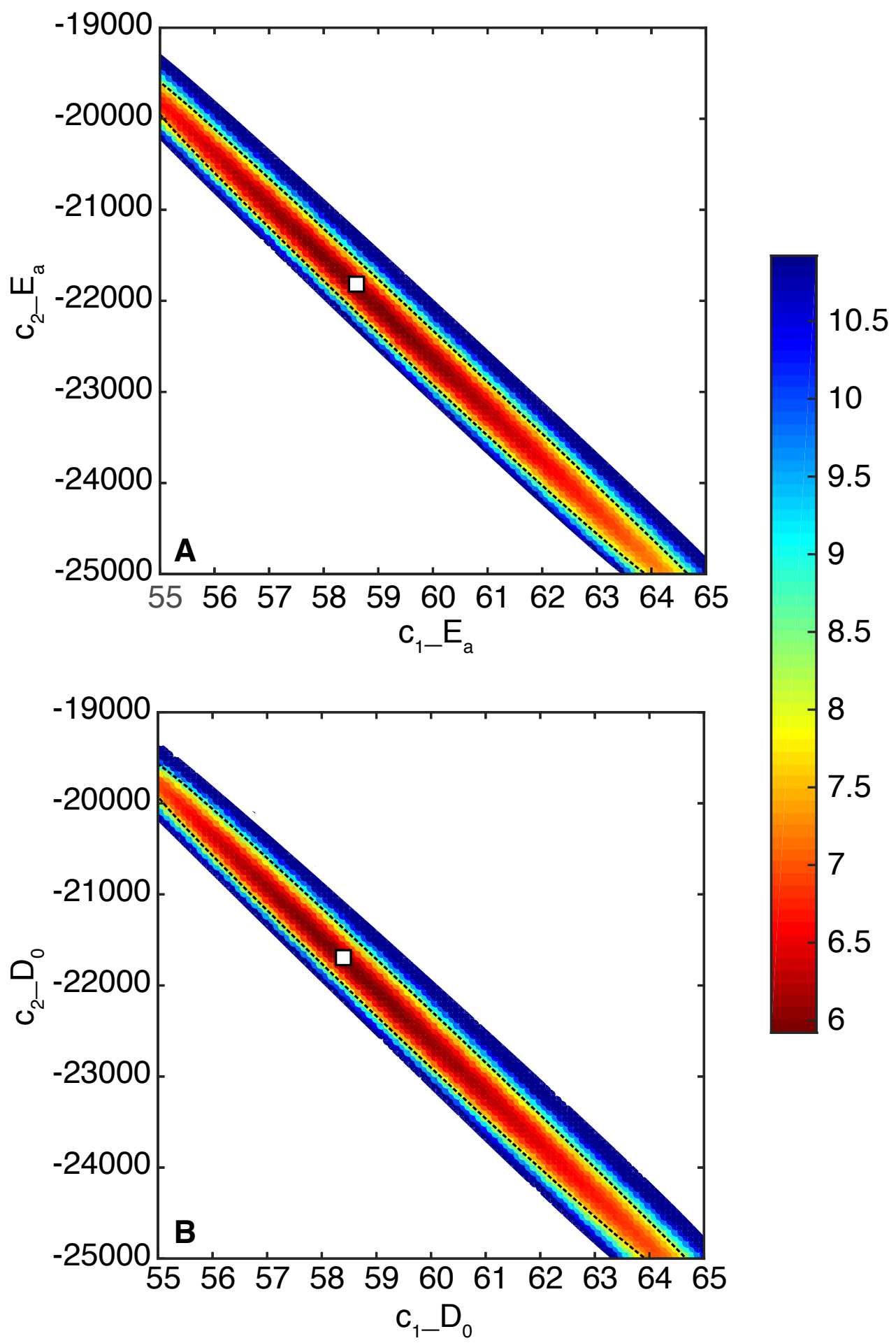


Figure 3

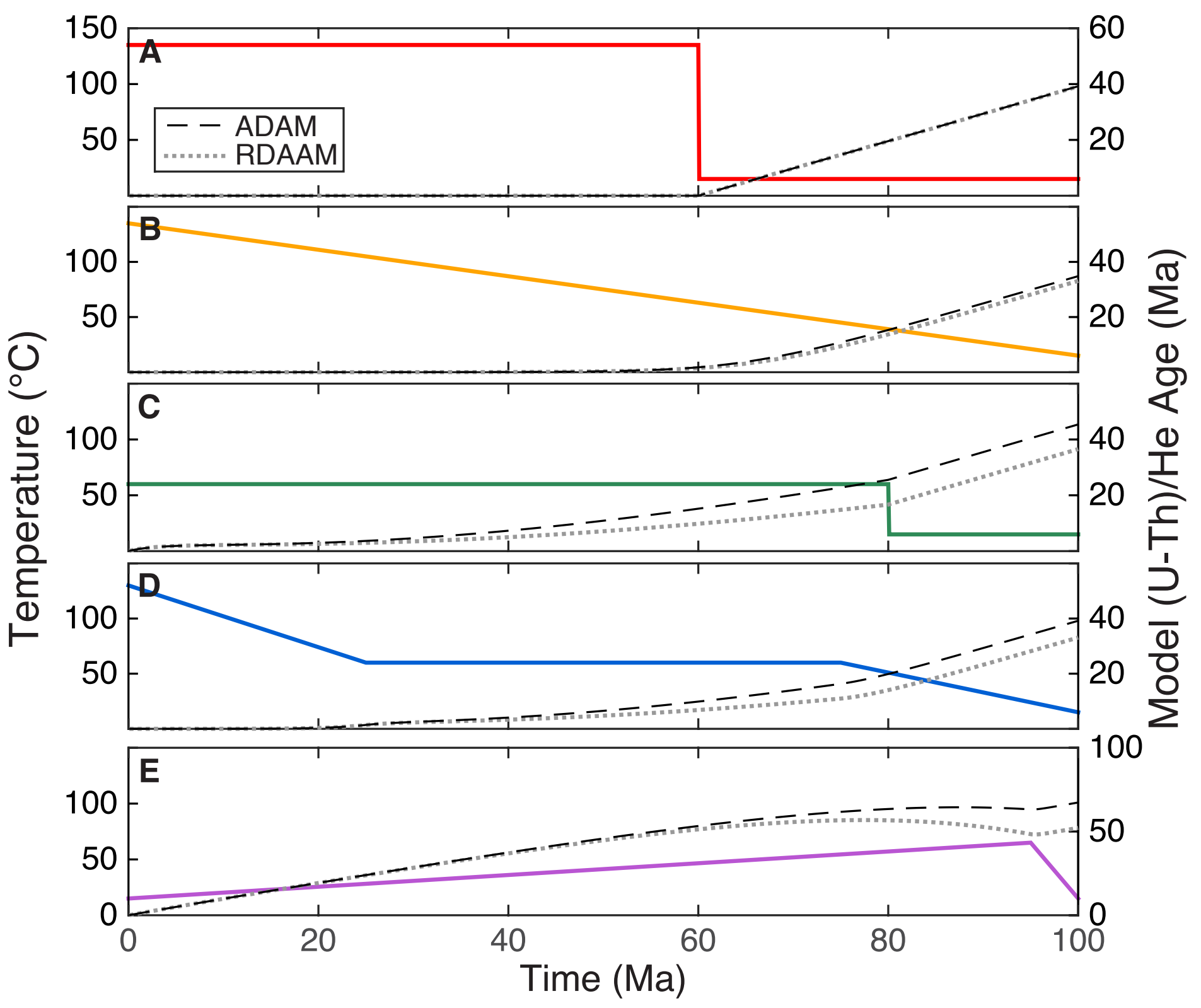




\section{Figure 4}

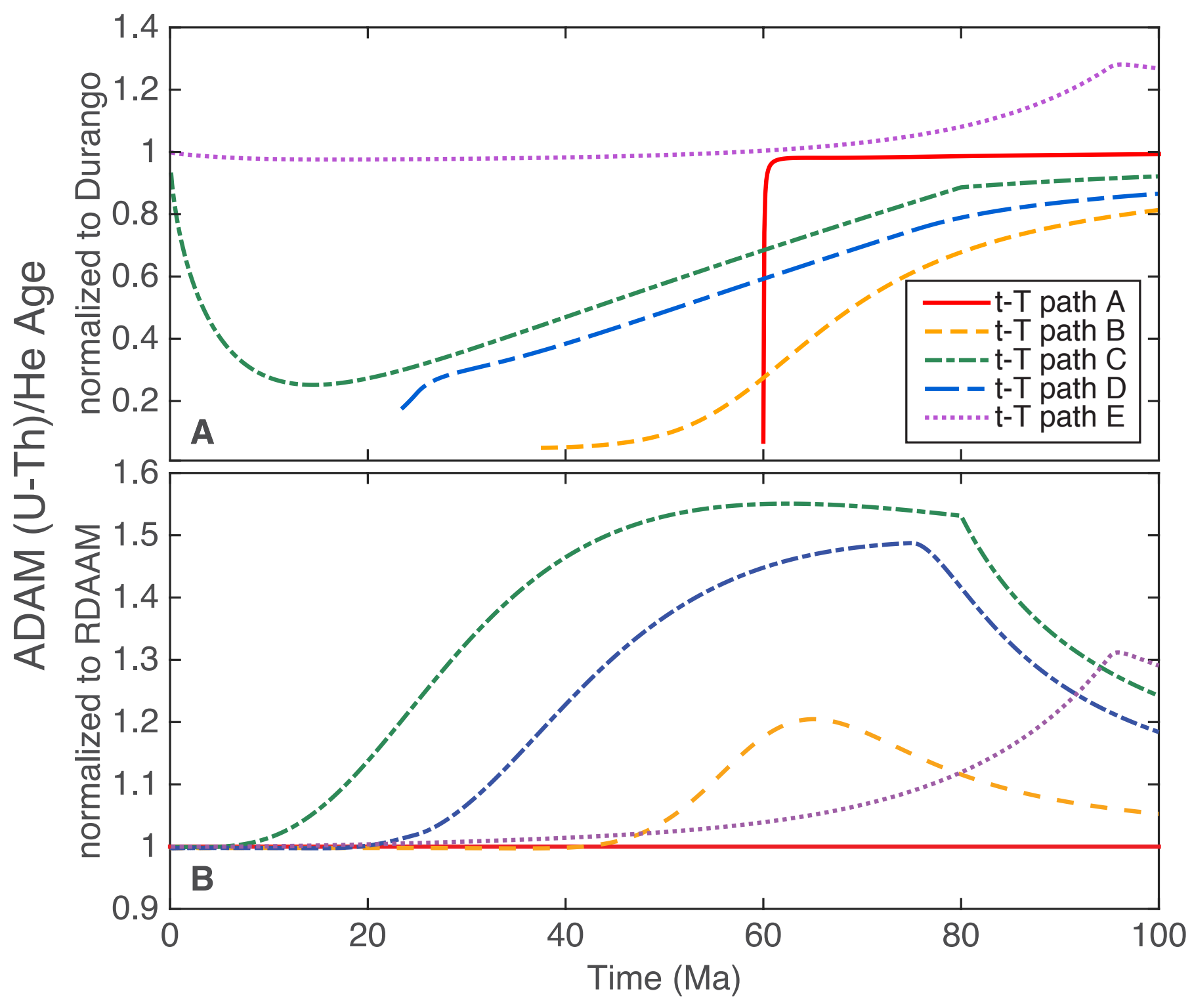


Figure 5
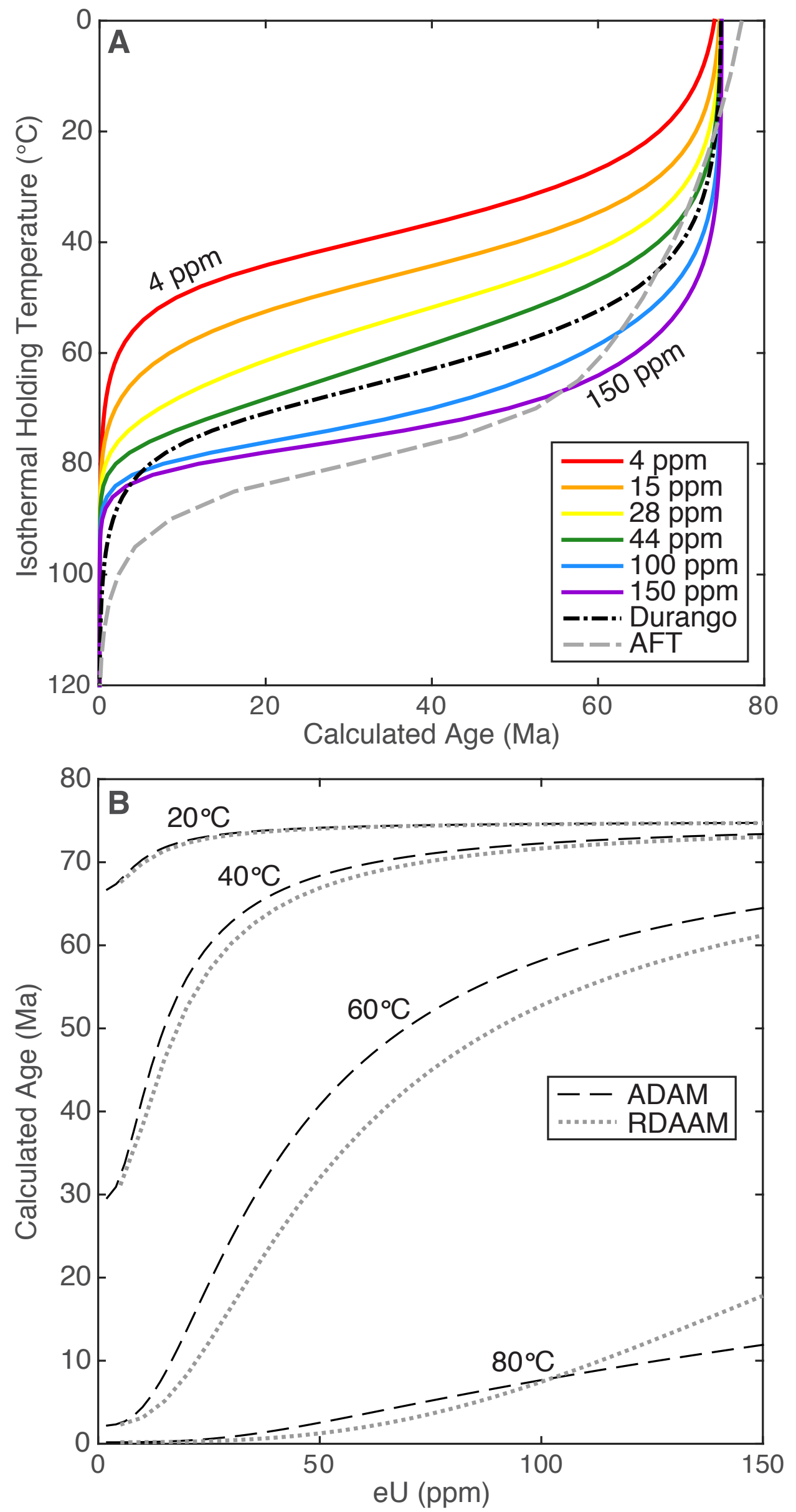
Figure 6
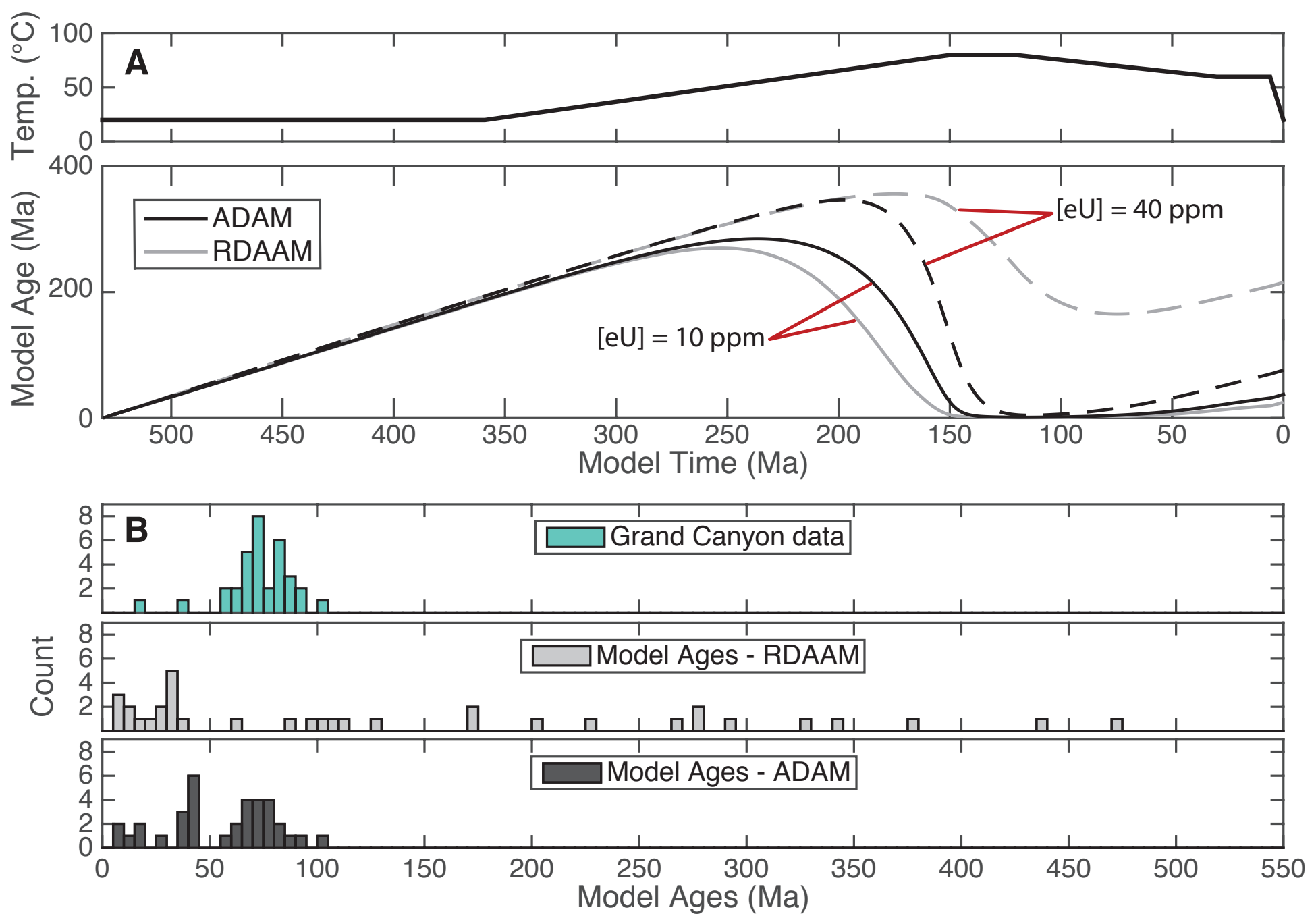
Figure 7

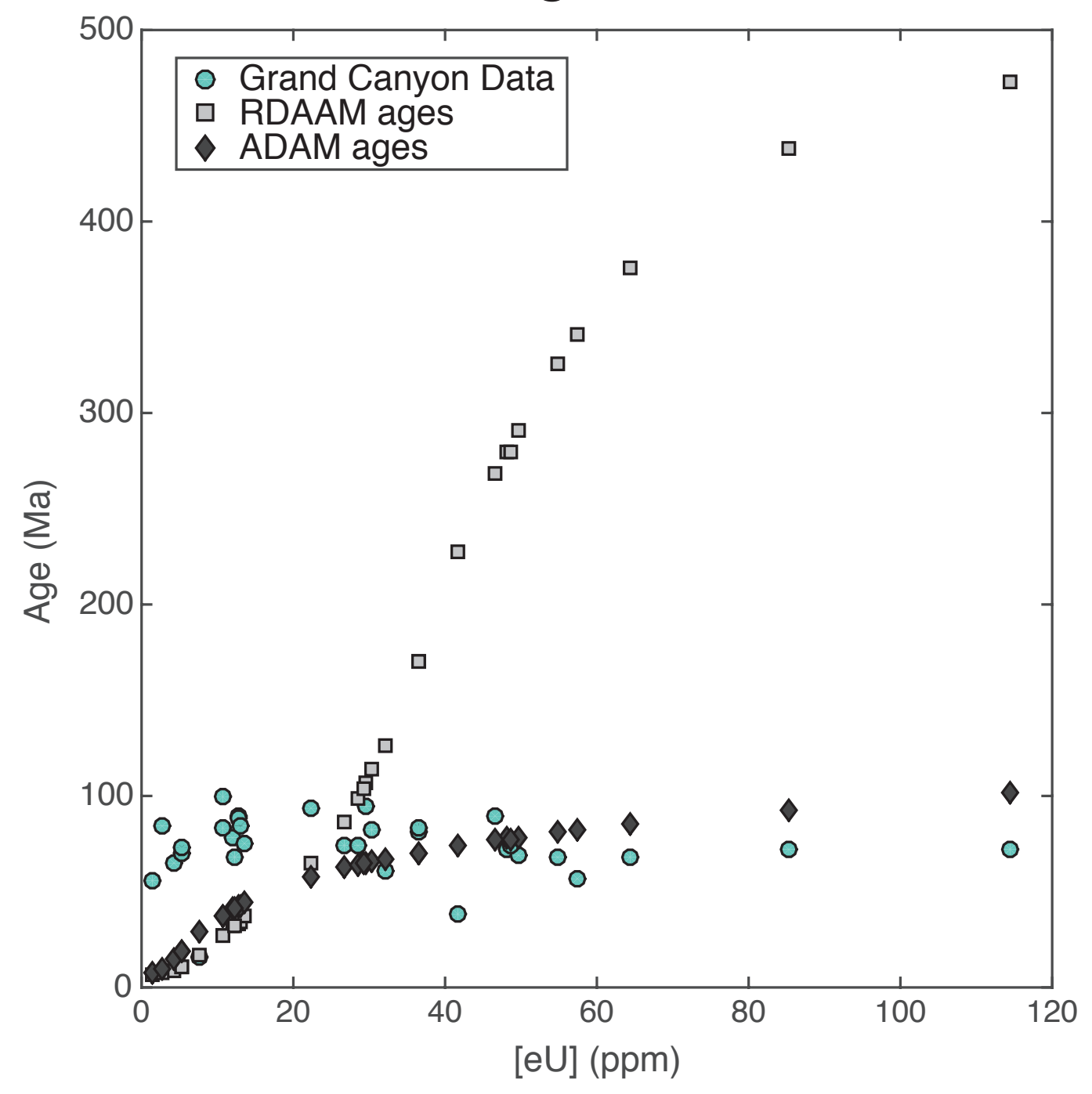


Supplementary material for online publication only

Click here to download Supplementary material for online publication only: Willett_EPSL_SupplementaryMaterial.pdf 